\title{
Digital cholangioscopy can detect residual biliary stones missed by occlusion cholangiogram in ERCP: a prospective tandem study
}

\section{(ㄷ)(우우}

\author{
Authors \\ Divyesh V. Sejpal', , Arvind J. Trindade ${ }^{2,3}$, Calvin Lee ${ }^{1,2}$, Larry S. Miller 2,3, Petros C. Benias ${ }^{1,2}$, Sumant Inamdar ${ }^{1,2}$, \\ Gurshawn Singh ${ }^{1,2}$, Molly Stewart ${ }^{1,2}$, Benley J. George ${ }^{1,2}$, Anil K. Vegesna ${ }^{3,4}$
}

Institutions

1 Division of Gastroenterology, North Shore University Hospital, Manhasset, New York, United States

2 Zucker School of Medicine at Hofstra/Northwell, Hempstead, New York, United States

3 Long Island Jewish Medical Center, New Hyde Park, New York, United States

4 The Feinstein Institute for Medical Research

submitted 15.10 .2018

accepted after revision 7.1.2019

Bibliography

DOI https://doi.org/10.1055/a-0842-6450 |

Endoscopy International Open 2019; 07: E608-E614

(c) Georg Thieme Verlag KG Stuttgart · New York

ISSN 2364-3722

Corresponding author

Divyesh Sejpal, MD, MHCDS, FASGE, FACG, AGAF, Professor of Medicine, Chief of Endoscopy, Northwell Health, Zucker School of Medicine at Hofstra/Northwell

Fax: +1-516-562-2683

Dsejpal@northwell.edu

ABSTRACT

Background and study aims After stone removal in endoscopic retrograde cholangiopancreatography (ERCP), an occlusion cholangiogram (OC) is performed to confirm bile duct clearance. OC can miss residual stones that can lead to recurrent biliary symptoms. The aim of this study was to assess if digital peroral cholangioscopy (POC) increased the diagnostic yield of residual biliary stones that are missed with OC.

Patients and methods Patients having ERCP performed for choledocholithiasis were enrolled into the study only if they had one of the following criteria: dilated bile duct $\geq 12 \mathrm{~mm}$ and/or if lithotripsy was being performed. An OC was performed to confirm duct clearance after removal of stones followed by POC, based on inclusion criteria. The incremental yield of biliary stones missed by OC but confirmed by POC was then measured. A total of 96 POC procedures were performed on 93 patients in two tertiary care centers.

Results Residual biliary stones were found in 34\% of cases. The average bile duct size in cases with residual stones was $15.1 \mathrm{~mm} \pm 0.7 \mathrm{~mm}$. One- to three-mm stones were found in $41 \%$ of cases, 4 - to $7-\mathrm{mm}$ stones in $45 \%$ of cases, and $\geq 8-\mathrm{mm}$ stones in $14 \%$ of cases. Lithotripsy was performed in $13 \%$ of cases and was significantly associated with residual stones ( $30 \%$ vs. $3 \%, P<0.001$ ).

Conclusions Occlusion cholangiogram can miss residual stones in patients with dilated bile ducts and those receiving lithotripsy. Digital POC can increase the yield of residual stone detection in these patients and should be considered to confirm clearance of stones. (ClinicalTrials.govNCT03482375).

\section{Introduction}

Gallstone disease affects over 20 million Americans [1]. Among patients with gallbladder disease, prevalence of choledocholithiasis is estimated to be $10 \%$ to $20 \%$ [2,3] Endoscopic retrograde cholangiopancreatography (ERCP) is considered the standard of care for removing stones in the bile duct utilizing a variety of conventional methods including biliary sphincterotomy, balloon dilation, extraction balloon, retrieval basket, and lithotripsy. After removal of stones from the bile duct, a balloon occlusion cholangiogram is usually performed to confirm complete bile duct clearance. However, occlusion cholangiogram (OC) can miss residual stones in $11 \%$ to $30 \%$ of cases, especially in the setting of a dilated bile duct, severe pneumobilia, and after lithotripsy (mechanical, electrohydraulic, or laser) [4-8]. Missed bile duct stones can lead to recurrent biliary symptoms, pancreatitis, cholangitis, and can have significant cost implication with the need for repeat imaging and/or procedures [4].

Peroral cholangioscopy (POC) enables direct visualization of the bile duct and allows for diagnostic and therapeutic maneu- 
vers. Although POC has been available for over 30 years, it did not become a widespread technique due to the fact that traditional cholangioscopes are fragile, cumbersome to use, and require two endoscopists to perform the procedure. Introduction of a single-operator semi-disposable, fiberoptic cholangioscope system (SpyGlass, Boston Scientific, Marlborough, Massachusetts, United States) addressed many of the concerns associated with traditional cholangioscopes and led to more widespread use of cholangioscopy $[5,9,10]$; however, the suboptimal image quality limited its application. Recent introduction of a completely disposable digital version of the Spyglass system has significantly improved image quality, thus augmenting the diagnostic and therapeutic capabilities of cholangioscopy $[11,12]$.

Given the substantial miss rate of residual stones on $\mathrm{OC}$, it has been proposed that digital POC may be beneficial for detecting residual stones, especially in the setting of a dilated bile duct or lithotripsy. The goal of this prospective study was to assess whether digital POC would increase the diagnostic yield of residual biliary stones that are missed with OC during conventional ERCP.

\section{Patients and methods}

\section{Patients}

This was a prospective tandem study conducted at two large academic tertiary care hospitals that are part of Northwell Health System (Long Island, New York, United States). The study was approved by the Northwell Health Institutional Review Board and all patients signed informed consent prior to participating. All patients were scheduled for standard-of-care endoscopy. Inclusion criteria were suspected or documented choledocholithiasis and: 1 ) dilated bile duct $\geq 12 \mathrm{~mm}$ (any portion of duct); and/or 2) the patient underwent mechanical lithotripsy (ML) or electrohydraulic lithotripsy (EHL) for therapy of bile duct stones. Patients younger than age 18 years or who had altered anatomy including Billroth II, Roux-en-Y Gastric bypass, and Whipple procedure were excluded.

\section{Procedure}

All ERCPs were performed under general anesthesia per the institutional standard of care. Five therapeutic endoscopists with formal training in advanced endoscopy performed the procedures (DS, AT, CL, LM, and PB). All procedures were performed with a Philips Veradius fluoroscopy C-arm with flat detector. Standard-of-care ERCP was performed with cannulation of the bile duct and cholangiogram to identify any biliary stones. If stones were identified, they were removed with conventional methods such as sphincterotomy, balloon extraction, basket retrieval, and/or lithotripsy. It is our standard practice to sweep the bile duct several times with a balloon prior to OC to remove any residual stones. After the endoscopist thought the bile duct was cleared, an OC was performed with the balloon size being determined by the duct diameter. The concentration of contrast was left to the discretion of the individual endoscopist's standard of care. If the OC was negative, and if patient met enrollment criteria, digital POC (SpyGlass DS, Boston Scientific,
Marlborough, Massachusetts, United States) was performed to assess for residual stones. All operators are experienced in cholangioscopy and have performed at least 30 exams prior to initiation of the study. The single-use disposable cholangioscope was then inserted under endoscopic and fluoroscopic guidance over a wire just proximal to the bile duct hilum. The catheter is 10.5 $\mathrm{Fr}$ in diameter, has a four-way tip control, (the catheter handle includes two control knobs for left-right and up-down tip deflection), two channels for water infusion and suction, and a single 1.2-mm working channel. After adequate visualization of the bile duct was achieved, the scope was slowly pulled back carefully examining the entire bile duct. The endoscopists were instructed to examine the right and left hepatic ducts, the hilum, the common hepatic duct, the common bile duct, and the cystic duct/stump takeoff.

Any residual stones that were documented by POC were removed or treated, such as with stone extraction, lithotripsy, or stent placement. All patients that received POC were given one dose of intravenous antibiotic during the procedure because of the associated risk of bacteremia [13].

The primary aim of this study was to determine the incremental yield of digital POC in detection of residual biliary stones that were not detected on an OC. Patients with residual stones detected on POC after OC were defined as the positive $\mathrm{POC}$ group. Patients without residual stones on $\mathrm{POC}$ after $\mathrm{OC}$ were defined as the negative POC group.

\section{Statistical analysis}

Based on the literature, it is estimated that between $11 \%$ and $30 \%$ of these patients will have stones identified on POC that were missed by conventional ECRP. If the percent of patients with missed stones is $30 \%$, then the $95 \%$ exact binomial confidence intervals for the proposed sample size of 100 subjects is $21.2 \%$ to $40.0 \%$. Due to the expected screen failure rate (eg: - Bile duct size $<12 \mathrm{~mm}$ etc.) of approximately $30 \%$ to $40 \%$, we planned to enroll a total of 140 subjects.

Continuous variables were expressed as a mean ( \pm Standard Error). Statistical comparisons between them were performed using an unpaired Student's $t$-test. Categorical variables were expressed as percentages. Comparisons between nominal variables were performed using the chi-squared test. When two variables were dichotomous, Fisher's exact test was used. When \% of expected count less than five, is more than $25 \%$, then Phi and Cramer's V was used. A $P$ value $<0.05$ was considered statistically significant.

All calculations were made using the SPSS 22 statistical package (SPSS Inc., Chicago, Illinois, United States).

\section{Results}

From January 2016 to February 2018, 140 patients with suspected or documented choledocholithiasis were enrolled into the study, of which 93 patients met inclusion criteria of dilated bile duct $\geq 12$ and/or lithotripsy being performed. Analysis was performed on a total of 96 procedures from the 93 patients. Patient characteristics are listed in $>$ Table 1 . Three patients had repeat procedures because biliary stents were placed after de- 
- Table 1 Demographics and patient characteristics.

\begin{tabular}{|c|c|c|c|c|c|c|c|}
\hline & & $\begin{array}{l}\text { Total qualified } \\
\text { procedures }\end{array}$ & Negative POC & Positive POC & $P$ value & $\begin{array}{l}\text { Positive POC } \\
\text { with stones } \\
\geq 4 \mathrm{~mm}\end{array}$ & $P$ value \\
\hline & Count & 96 (100\%) & $63(66 \%)$ & $33(34 \%)$ & & $20(21 \%)$ & \\
\hline & Age & $65.1 \pm 1.7$ & $64.2 \pm 2.3$ & $66.9 \pm 2.6$ & 0.47 & $66.5 \pm 3.6$ & 0.61 \\
\hline \multirow[t]{2}{*}{ Gender } & Male & $33(34 \%)$ & $19(30 \%)$ & $14(42 \%)$ & \multirow[t]{2}{*}{0.23} & $9(45 \%)$ & \multirow[t]{2}{*}{0.22} \\
\hline & Female & $63(66 \%)$ & $44(70 \%)$ & $19(58 \%)$ & & $11(55 \%)$ & \\
\hline \multirow[t]{3}{*}{ Ethnicity } & Hispanic & $17(18 \%)$ & $14(23 \%)$ & $3(9 \%)$ & \multirow[t]{3}{*}{0.26} & $0(0 \%)$ & \multirow[t]{3}{*}{0.07} \\
\hline & Non-Hispanic & 67 (71\%) & $41(66 \%)$ & $26(79 \%)$ & & 17 (85\%) & \\
\hline & Not reported & $11(12 \%)$ & $7(11 \%)$ & $4(12 \%)$ & & $3(15 \%)$ & \\
\hline \multicolumn{2}{|l|}{ BMI } & $27.7 \pm 0.7$ & $27.6 \pm 0.8$ & $27.7 \pm 1.1$ & 0.96 & $29.2 \pm 1.4$ & 0.33 \\
\hline \multirow[t]{3}{*}{$\begin{array}{l}\text { Inclusion } \\
\text { criteria }\end{array}$} & $\begin{array}{l}\text { Bile duct size } \geq 12 \mathrm{~mm} \\
\text { only }\end{array}$ & $84(88 \%)$ & $61(97 \%)$ & $23(70 \%)$ & $<0.001^{1}$ & $13(65 \%)$ & $0.006^{1}$ \\
\hline & Lithotripsy only & $2(2 \%)$ & $0(0 \%)$ & $2(6 \%)$ & $0.048^{1}$ & $2(10 \%)$ & $0.011^{1}$ \\
\hline & $\begin{array}{l}\text { Both bile duct size } \geq \\
12 \mathrm{~mm} \text { and had lithotripsy }\end{array}$ & $10(10 \%)$ & $2(3 \%)$ & $8(24 \%)$ & $0.001^{1}$ & $5(25 \%)$ & 0.08 \\
\hline \multicolumn{2}{|c|}{ History of cholecystectomy } & $44(46 \%)$ & $28(44 \%)$ & $16(49 \%)$ & 0.71 & $11(55 \%)$ & 0.41 \\
\hline \multirow{8}{*}{$\begin{array}{l}\text { Past treat- } \\
\text { ment }\end{array}$} & ERCP & $64(67 \%)$ & $39(62 \%)$ & $25(76 \%)$ & 0.17 & $15(75 \%)$ & 0.29 \\
\hline & Balloon extraction & $37(39 \%)$ & $25(40 \%)$ & $12(36 \%)$ & 0.75 & $6(30 \%)$ & 0.44 \\
\hline & Lithotripsy & $13(14 \%)$ & $6(10 \%)$ & $7(21 \%)$ & 0.11 & $5(25 \%)$ & 0.08 \\
\hline & Sphincterotomy & $26(27 \%)$ & $17(27 \%)$ & $9(27 \%)$ & 0.98 & $4(20 \%)$ & 0.53 \\
\hline & Balloon dilation & $7(7 \%)$ & $4(6 \%)$ & $3(9 \%)$ & 0.63 & $1(5 \%)$ & 0.83 \\
\hline & Basket retrieval & $3(3 \%)$ & $3(5 \%)$ & $0(0 \%)$ & 0.11 & $0(0 \%)$ & 0.32 \\
\hline & Biliary stent & $47(49 \%)$ & $27(43 \%)$ & $20(61 \%)$ & 0.09 & $12(60 \%)$ & 0.18 \\
\hline & Other & $3(3 \%)$ & $1(2 \%)$ & $2(6 \%)$ & 0.25 & $1(5 \%)$ & 0.39 \\
\hline \multirow[t]{6}{*}{ LABS } & Total bilirubin & $2.8 \pm 0.4$ & $2.4 \pm 0.4$ & $3.4 \pm 0.9$ & 0.26 & $3.7 \pm 0.7$ & 0.12 \\
\hline & Direct bilirubin & $2.1 \pm 0.3$ & $2.2 \pm 0.5$ & $1.8 \pm 0.4$ & 0.53 & $1.9 \pm 0.5$ & 0.70 \\
\hline & Indirect bilirubin & $1.2 \pm 0.2$ & $1.4 \pm 0.3$ & $1.1 \pm 0.2$ & 0.75 & $1.3 \pm 0.17$ & 0.97 \\
\hline & Alkaline phosphatase & $221.3 \pm 17.6$ & $196 \pm 20.6$ & $270.3 \pm 31.7$ & $0.04^{1}$ & $293 \pm 39.8$ & $0.03^{1}$ \\
\hline & ALT & $187.1 \pm 20.5$ & $177.9 \pm 21.6$ & $205.3 \pm 43.8$ & 0.53 & $180.7 \pm 37.9$ & 0.95 \\
\hline & AST & $154.2 \pm 20.9$ & $159.2 \pm 26.1$ & $144.3 \pm 33.5$ & 0.74 & $118.5 \pm 27.1$ & 0.42 \\
\hline \multirow{2}{*}{$\begin{array}{l}\text { Patient } \\
\text { location }\end{array}$} & Inpatient & $33(35 \%)$ & $23(37 \%)$ & $10(30 \%)$ & \multirow[t]{2}{*}{0.51} & $7(35 \%)$ & \multirow[t]{2}{*}{0.87} \\
\hline & Outpatient & $62(65 \%)$ & $39(63 \%)$ & $23(70 \%)$ & & $13(65 \%)$ & \\
\hline
\end{tabular}

tection and/or lithotripsy of stones; these patients met inclusion criteria on their subsequent ERCP.

The main indication for performing POC was presence of a dilated bile duct $\geq 12 \mathrm{~mm}$ ( $88 \%$ ), followed by a combination of dilated bile duct $\geq 12 \mathrm{~mm}$ and lithotripsy (10\%), and lithotripsy only $(2 \%)$. Thirty-four percent of the cases had residual stones seen on POC ( $>$ Table 2, $>$ Fig. 1, $>$ Fig. 2). In patients with positive POC, the average total number of stones was $1.6+\mid-0.1$ with most stones seen in the common bile duct (67\%), followed by hilum (15\%), cystic stump (12\%) and common hepatic duct (6\%). Average stone size was $4.2 \mathrm{~mm}+1-0.3 \mathrm{~mm}$, median 4.0 , range $1-10 \mathrm{~mm}$. One- to $3-\mathrm{mm}$ stones were found in $41 \%$ of 
- Table 2 POC characteristics/findings in patients with residual stones.

\begin{tabular}{|c|c|c|c|}
\hline & & $\begin{array}{l}\text { Positive } \mathrm{POC} \\
\mathrm{N}=33 \text { cases }(34 \%)\end{array}$ & $\begin{array}{l}\text { Positive POC with stones } \\
\geq 4 \mathrm{~mm}(\mathrm{~N}=20)\end{array}$ \\
\hline \multirow[t]{4}{*}{ Location of stones } & Common hepatic duct & $2(6 \%)$ & $1(5 \%)$ \\
\hline & Common bile duct & $22(67 \%)$ & $13(65 \%)$ \\
\hline & Hilum & $5(15 \%)$ & $3(15 \%)$ \\
\hline & Cystic stump & $4(12 \%)$ & $3(15 \%)$ \\
\hline \multicolumn{2}{|c|}{ Average number of stones per patient } & $1.6 \pm 0.1$ & $1.6 \pm 0.2$ \\
\hline \multicolumn{2}{|l|}{ Average stone size (mm) } & $\begin{array}{l}4.2 \pm 0.3 \\
\text { (Range } 1 \text { to } 10) \\
\text { (Median } 4 \text { ) }\end{array}$ & $\begin{array}{l}5.6 \pm 0.3 \\
\text { (Range } 4 \text { to 10) } \\
\text { (Median 5) }\end{array}$ \\
\hline \multirow[t]{3}{*}{ Grouping based on stone sizes } & Stone size 1 to $3 \mathrm{~mm}$ & $21(41 \%)$ & - \\
\hline & Stone size 4 to $7 \mathrm{~mm}$ & $23(45 \%)$ & $23(77 \%)$ \\
\hline & Stone size $\geq 8 \mathrm{~mm}$ & $7(14 \%)$ & $7(23 \%)$ \\
\hline \multirow[t]{9}{*}{ Treatment after POC } & Balloon extraction & $24(73 \%)$ & $15(75 \%)$ \\
\hline & Biliary stent placement & $8(24 \%)$ & $4(20 \%)$ \\
\hline & Lithotripsy & $6(18 \%)$ & $4(20 \%)$ \\
\hline & - Mechanical & $0(0 \%)$ & $0(0 \%)$ \\
\hline & " EHL & $6(18 \%)$ & $4(20 \%)$ \\
\hline & Sphincterotomy & $1(3 \%)$ & $1(5 \%)$ \\
\hline & Balloon dilatation & $2(6 \%)$ & $1(5 \%)$ \\
\hline & Basket retrieval & $0(0 \%)$ & $0(0 \%)$ \\
\hline & Other & $1(3 \%)$ & $1(5 \%)$ \\
\hline
\end{tabular}

cases, 4 - to $7-\mathrm{mm}$ stones in $45 \%$ of cases, and $\geq 8$-mm stones in $14 \%$ of cases.

The average bile duct size in the positive and negative POC groups was not statistically different $(15.1 \pm 0.7$, range $11-30$ $\mathrm{mm}$ and $14.3 \pm 0.2$, range $12-20 \mathrm{~mm} ; P=0.2$ ) ( $\triangleright$ Table 3 ). When evaluating bile duct sizes (ranging from $11-30 \mathrm{~mm}$ ), no one size was statistically associated with residual stones. Average stone size initially seen on ERCP prior to POC was significantly larger in the POC-positive group vs. the POC-negative group $(9.6 \mathrm{~mm} \pm 0.9 \mathrm{~mm}$ vs. $6.7 \mathrm{~mm} \pm 0.4 \mathrm{~mm}, P=.001)$. When evaluating stone shapes, cuboidal stones were significantly associated with the positive POC group (30\% vs. $12 \%, P=$ 0.003). Lithotripsy (both EHL and ML) was performed in $13 \%$ of cases and was significantly associated with the positive POC group ( $30 \%$ vs. $3 \%, P<0.001)$. A subgroup analysis of patients with stones $\geq 4 \mathrm{~mm}$ in the positive $\mathrm{POC}$ group was also performed and compared to the negative POC group ( $\downarrow$ Table 1 , - Table 2, Table 3); the findings were similar as all patients with residual stones except that the percentage of cuboidal stones was less.

There were a total of three adverse events (AEs) that were related to the procedure. In the positive POC group, one patient had cholangitis which was classified as "mild" based on Ameri- can Society of Gastrointestinal Endoscopy guidelines on AEs associated with ERCP (the patient was admitted and discharged the next day with $\mathrm{PO}$ antibiotics for 7 days). In the negative POC group, two patients had "moderate" pancreatitis, which was classified based on consensus definition and classification proposed by Cotton et al $[14,15]$.

\section{Discussion}

ERCP cholangiogram is considered the reference standard for diagnosis of choledocholithiasis. In fact, most studies evaluating EUS and magnetic resonance cholangiopancreatography for detection of choledocholithiasis use ERCP cholangiogram or intraoperative cholangiography as the "gold standard" for presence or absence of biliary stones [16-23]. However, ERCP cholangiogram and intraoperative cholangiography have been reported to miss stones, especially in the setting of a dilated bile duct or when lithotripsy is performed [6,24,25]. Thus, ERCP cholangiogram may not be sensitive enough to confirm clearance of the bile duct in these settings.

Peroral cholangioscopy provides direct visualization of the bile duct during ERCP and its benefits are well documented in numerous published studies. POC is most commonly per- 

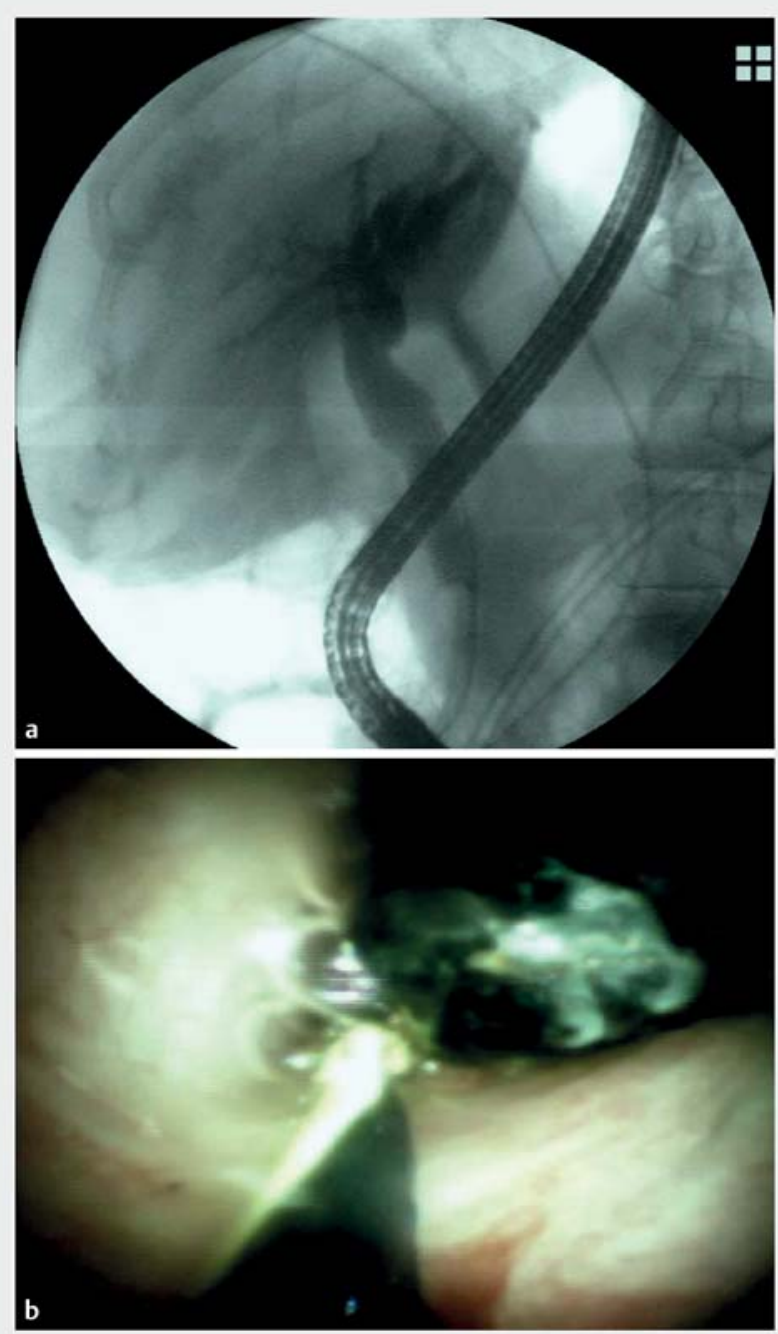

- Fig. 1 a Negative occlusion cholangiogram in a dilated bile duct after removal of multiple stones. b Digital cholangioscopy showing a $6-\mathrm{mm}$ residual stone in the common bile duct.

formed for management of difficult biliary stones and for evaluation of biliary strictures [11]. However, POC has also been described in evaluation of residual stones that are missed with cholangiogram. In a multicenter study evaluating POC for a variety of indications, $11 \%$ of patients (7/66) had bile duct stones identified only by POC that were missed on ERCP [5]. In a study of patients with primary sclerosing cholangitis, $30 \%$ of patients (7/23) were found to have stones with POC that were missed with cholangiography [26]. Lee et al. analyzed a group of 64 patients that had undergone mechanical lithotripsy and found that $28.3 \%(13 / 46)$ had residual stones seen with POC that were missed with an OC [7]. Itoi et al. assessed residual bile duct stones found with POC in comparison to balloon cholangiography in a retrospective study of 108 patients; they found that $24 \%$ of patients $(26 / 108)$ had residual stones seen with POC that were missed with balloon-occluded cholangiography [6]. The residual stones ranged in size from 2 to $8 \mathrm{~mm}$ with a mean of $4.8 \mathrm{~mm}$. The authors found that frequency of

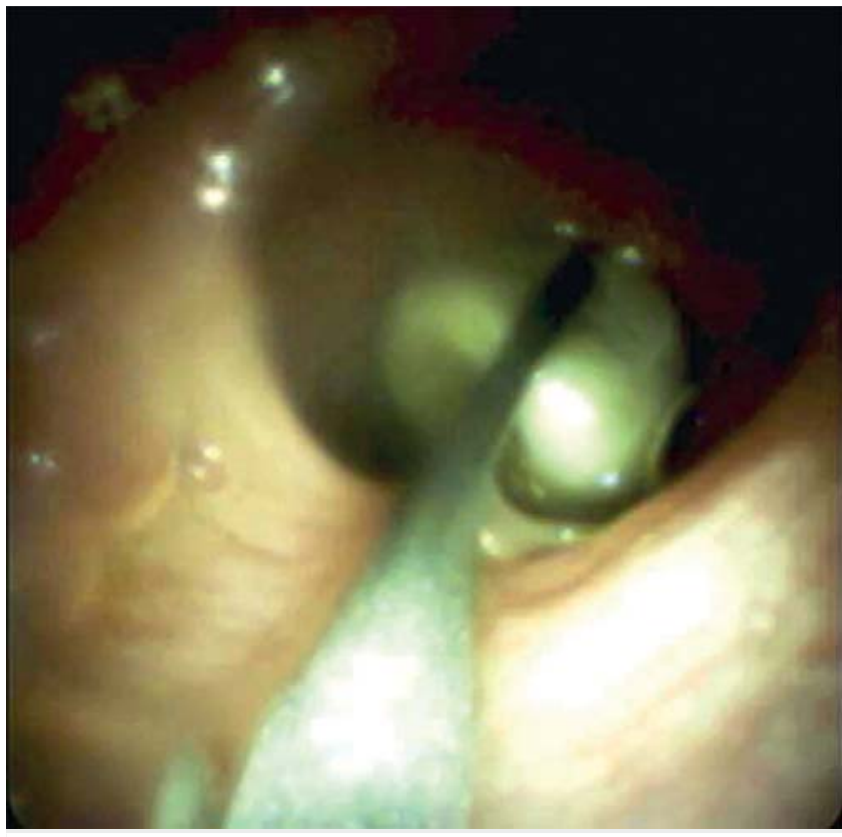

- Fig. 2 Digital cholangioscopy showing a residual stone that was found within the cystic stump.

missed stones was significantly higher with large stone size, presence of juxtapapillary diverticulum, and when $\mathrm{ML}$ or $\mathrm{EHL}$ was performed. In a small prospective study of 22 patients, Haung et al. showed that $22.7 \%$ (5/22) had residual stones detected with POC after a negative balloon-occluded cholangiography [27]. Because of the small sample size, no statistical analysis was performed. However, the residual stones ranged from 2 to $5 \mathrm{~mm}$ with a mean bile duct diameter of $19 \mathrm{~mm}$ in these patients.

Our study is the largest prospective study to date that evaluated digital POC in detecting residual stones in dilated bile ducts and/or lithotripsy patients that are missed with conventional ERCP. In our study, 34\% of cases were found to have residual stones that were seen on POC but missed with an OC. Large stone size $(>9 \mathrm{~mm})$, cuboidal stones, and lithotripsy were all significantly associated with residual stones. The average bile duct size in cases with residual stones was $15.1 \mathrm{~mm} \pm$ $0.7 \mathrm{~mm}$. We attempted to clarify patients by degree of bile duct dilation (e.g. $>15 \mathrm{~mm}$ ), but found no correlation with residual stones. However, our sample size was not powered to find a relationship between specific duct size and residual stones.

In $12 \%$ of the positive POC cases, residual stones were found in or at the cystic stump in post-cholecystectomy patients. POC may potentially play an important role in detection of residual stones in the setting of a dilated cystic stump, especially when there is a low take-off from the bile duct. Presumably, these stones can ball-valve in and out of the cystic stump into the main bile duct and cause recurrent symptoms.

The strengths of this study include the prospective tandem design, large sample size for this type of study, and inclusion of multiple endoscopists that increases the generalizability of our study. The main limitation of the study is that we cannot 
- Table 3 ERCP procedure characteristics.

\begin{tabular}{|c|c|c|c|c|c|c|c|}
\hline & & $\begin{array}{l}\text { Total qua- } \\
\text { lified pro- } \\
\text { cedures }\end{array}$ & $\begin{array}{l}\text { Negative } \\
\text { POC }\end{array}$ & $\begin{array}{l}\text { Positive } \\
\text { POC }\end{array}$ & $P$ value & $\begin{array}{l}\text { Positive POC } \\
\text { with stones } \\
\geq 4 \mathrm{~mm}\end{array}$ & $P$ value \\
\hline $\begin{array}{l}\text { Juxtapapillary } \\
\text { diverticulum }\end{array}$ & & $4(4 \%)$ & $3(5 \%)$ & $1(3 \%)$ & 0.69 & $1(3 \%)$ & 0.97 \\
\hline $\begin{array}{l}\text { Biliary stent present } \\
\text { at time of index ERCP }\end{array}$ & & $48(50 \%)$ & $27(43 \%)$ & $21(64 \%)$ & $0.05^{1}$ & $13(65 \%)$ & 0.08 \\
\hline \multirow[t]{5}{*}{ Bile duct size (mm) } & Average & $14.5 \pm 0.3$ & $14.3 \pm 0.2$ & $15.1 \pm 0.7$ & 0.2 & $15.5 \pm 1.1$ & 0.13 \\
\hline & Median & 14 & 14 & 15 & & 14 & \\
\hline & Range & $11-30$ & $12-20$ & $11-30$ & & $11-30$ & \\
\hline & $\geq 15 \mathrm{~mm}$ & $44 \%$ & $40 \%$ & $52 \%$ & 0.27 & $40 \%$ & 0.98 \\
\hline & $\geq 18 \mathrm{~mm}$ & $9 \%$ & $10 \%$ & $9 \%$ & 0.95 & $15 \%$ & 0.49 \\
\hline Stone size (mm) & Average & $7.6 \pm 0.4$ & $6.7 \pm 0.4$ & $9.6 \pm 0.9$ & $0.001^{1}$ & $8.9 \pm 1.2$ & $0.02^{1}$ \\
\hline \multirow[t]{4}{*}{ Stone shapes } & Round & $70(40 \%)$ & $44(40 \%)$ & $26(39 \%)$ & 0.84 & $16(53 \%)$ & 0.20 \\
\hline & Cuboidal & $33(19 \%)$ & $13(12 \%)$ & $20(30 \%)$ & $0.003^{1}$ & $4(13 \%)$ & 0.84 \\
\hline & Ovoid & $63(36 \%)$ & $43(40 \%)$ & $20(30 \%)$ & 0.12 & $9(30 \%)$ & 0.34 \\
\hline & Other & $10(6 \%)$ & $9(8 \%)$ & $1(2 \%)$ & 0.06 & $1(3 \%)$ & 0.36 \\
\hline \multirow[t]{9}{*}{ Treatment during ERCP } & Balloon extraction & 93 (97\%) & $63(100 \%)$ & 30 (91\%) & $0.015^{1}$ & $18(90 \%)$ & $0.011^{1}$ \\
\hline & Biliary stent placement & $6(6 \%)$ & $2(3 \%)$ & $4(12 \%)$ & 0.08 & $3(15 \%)$ & 0.07 \\
\hline & Lithotripsy & $12(13 \%)$ & $2(3 \%)$ & $10(30 \%)$ & $<0.001^{1}$ & $6(30 \%)$ & $<0.001^{1}$ \\
\hline & - Mechanical & $2(3 \%)^{2}$ & $1(2 \%)$ & $1(3 \%)^{2}$ & 0.64 & $1(5 \%)$ & 0.39 \\
\hline & - EHL & $11(11 \%)$ & $1(2 \%)$ & $10(30 \%)^{2}$ & $<0.001^{1}$ & $6(30 \%)$ & $<0.001^{1}$ \\
\hline & Sphincterotomy & $37(39 \%)$ & $28(44 \%)$ & $9(27 \%)$ & 0.10 & $5(25 \%)$ & 0.12 \\
\hline & Balloon dilatation & $16(17 \%)$ & $8(13 \%)$ & $8(24 \%)$ & 0.15 & $5(25 \%)$ & 0.19 \\
\hline & Basket retrieval & $2(2 \%)$ & $1(2 \%)$ & $1(3 \%)$ & 0.65 & $0(0 \%)$ & 0.57 \\
\hline & Other & $1(1 \%)$ & $0(0 \%)$ & $1(3 \%)$ & 0.17 & $0(0 \%)$ & $\ldots$ \\
\hline \multicolumn{8}{|c|}{$\begin{array}{l}\text { P values are based on comparing to patients with negative POC. } \\
\text { EHL, electrohydraulic lithotripsy; ERCP, endoscopic retrograde cholangiopancreatography } \\
1 \text { Significant } \\
2 \text { One patient had both mechanical lithotripsy and EHL }\end{array}$} \\
\hline
\end{tabular}

determine the clinical significance of missed residual stones. While there is no definitive way to know if the residual stones would be symptomatic if not detected and removed, we grouped the residual stones into categories based on their size and potential clinical relevance; 1 - to $3-\mathrm{mm}$ stones were seen in $41 \%$ of cases, 4 - to 7 -mm stones were seen in $45 \%$ of cases, and $8-\mathrm{mm}$ and greater stones were seen in $14 \%$ of cases. In general, $59 \%$ of stones seen on POC were $4 \mathrm{~mm}$ or greater and $23 \%$ of these were $\geq 8 \mathrm{~mm}$. We believe that these larger stones may have more clinical significance. The patients with stones $\geq 4 \mathrm{~mm}$ on $\mathrm{POC}$ were subdivided and compared to the negative POC group to identify risk factors for having larger residual stones; however, the findings were similar to all patients with residual stones. Some studies that have analyzed risk factors for recurrent biliary stones suggest that even small residual stone fragments might act as nidi for future stone formation and lead to recurrent stones [28-31].

Another limitation of the study is that it was not blinded as the same operator performed the $\mathrm{OC}$ and the subsequent POC. In addition, no cost analysis was performed; we did not address the direct cost of POC for detection of residual stones nor did we address potential cost savings from avoidance of repeat procedures or hospitalizations from residual stones. Also, the additional potential risk of performing POC on top of standard-ofcare ERCP was not addressed in this study. 


\section{Conclusion}

In conclusion, OC can miss residual stones in patients with dilated bile ducts and those receiving lithotripsy. Digital POC can increase the yield of residual stone detection in these patients and should be considered to confirm clearance of stones.

\section{Competing interests}

This study was an investigator-initiated study supported by a research grant from Boston Scientific Corporation. The sponsor was not involved in the clinical trial design, conduct of the trial, analysis of results, or preparation of the manuscript. Dr. Sejpal is a consultant for Boston Scientific and Olympus. Dr. Trindade is a consultant for Pentax Medical. Dr. Benias is a consultant for Apollo and Medtronic.

\section{References}

[1] Everhart JE, Khare M, Hill M et al. Prevalence and ethnic differences in gallbladder disease in the United States. Gastroenterology 1999; 117: $632-639$

[2] Lacaine F, Corlette MB, Bismuth $\mathrm{H}$. Preoperative evaluation of the risk of common bile duct stones. Arch Surg 1980; 115: 1114-1116

[3] Neuhaus $\mathrm{H}$, Feussner $\mathrm{H}$, Ungeheuer A et al. Prospective evaluation of the use of endoscopic retrograde cholangiography prior to laparoscopic cholecystectomy. Endoscopy 1992; 24: 745 - 749

[4] Awadallah NSBS, Chen YKMD, Piraka CMD et al. Is there a role for cholangioscopy in patients with primary sclerosing cholangitis? Am J Gastroenterol 2006; 101: 284-291

[5] Chen YK, Parsi MA, Binmoeller KF et al. Single-operator cholangioscopy in patients requiring evaluation of bile duct disease or therapy of biliary stones (with videos). Gastrointest Endosc 2011; 74: 805-814

[6] Itoi T, Sofuni A, Itokawa F et al. Evaluation of residual bile duct stones by peroral cholangioscopy in comparison with balloon-cholangiography. Dig Endosc 2010; 22: (Suppl. 01): S85-s89

[7] Lee YN, Moon JH, Choi H] et al. Direct peroral cholangioscopy using an ultraslim upper endoscope for management of residual stones after mechanical lithotripsy for retained common bile duct stones. Endoscopy 2012; 44: 819-824

[8] Maple JT, Ben-Menachem T, Anderson MA et al. The role of endoscopy in the evaluation of suspected choledocholithiasis. Gastrointest Endosc 2010; 71: 1 - 9

[9] Chen YK. Preclinical characterization of the Spyglass peroral cholangiopancreatoscopy system for direct access, visualization, and biopsy. Gastrointest Endosc 2007; 65: 303 - 311

[10] Chen YK, Pleskow DK. SpyGlass single-operator peroral cholangiopancreatoscopy system for the diagnosis and therapy of bile-duct disorders: a clinical feasibility study (with video). Gastrointest Endosc65: $832-841$

[11] Komanduri S, Thosani N, Abu Dayyeh BK et al. Cholangiopancreatoscopy. Gastrointest Endosc 2016; 84: 209-221

[12] Navaneethan U, Hasan MK, Kommaraju K et al. Digital, single-operator cholangiopancreatoscopy in the diagnosis and management of pancreatobiliary disorders: a multicenter clinical experience (with video). Gastrointest Endosc 2016; 84: 649-655
[13] Othman MO, Guerrero R, Elhanafi S et al. A prospective study of the risk of bacteremia in directed cholangioscopic examination of the common bile duct. Gastrointestinal endoscopy 2016; 83: 151-157

[14] Chandrasekhara V, Khashab MA. ASGE Standards of Practice Committee. et al. Adverse events associated with ERCP. Gastrointest Endosc 2017; 85: $32-47$

[15] Cotton PB, Lehman G, Vennes J et al. Endoscopic sphincterotomy complications and their management: an attempt at consensus. Gastrointest Endosc 1991; 37: 383-393

[16] Ainsworth AP, Rafaelsen SR, Wamberg PA et al. Is there a difference in diagnostic accuracy and clinical impact between endoscopic ultrasonography and magnetic resonance cholangiopancreatography? Endoscopy 2003; 35: 1029-1032

[17] de Ledinghen V, Lecesne R, Raymond JM et al. Diagnosis of choledocholithiasis: EUS or magnetic resonance cholangiography? A prospective controlled study Gastrointest Endosc 1999; 49: 26-31

[18] Fernandez-Esparrach GMDPD, Gines AMDPD, Sanchez MMD et al. Comparison of Endoscopic Ultrasonography and Magnetic Resonance Cholangiopancreatography in the Diagnosis of Pancreatobiliary Diseases: A Prospective Study. Am J Gastroenterol 2007; 102: 1632 1639

[19] Garrow D, Miller S, Sinha D et al. Endoscopic ultrasound: a meta-analysis of test performance in suspected biliary obstruction. Clin Gastroenterol Hepatol 2007; 5: 616-623

[20] Kondo S, Isayama H, Akahane $\mathrm{M}$ et al. Detection of common bile duct stones: comparison between endoscopic ultrasonography, magnetic resonance cholangiography, and helical-computed-tomographic cholangiography. Euro J Radiol 2005; 54: 271-275

[21] Materne R, Van Beers BE, Gigot JF et al. Extrahepatic biliary obstruction: magnetic resonance imaging compared with endoscopic ultrasonography. Endoscopy 2000; 32: 3-9

[22] Scheiman JM, Carlos RC, Barnett JL et al. Can endoscopic ultrasound or magnetic resonance cholangiopancreatography replace ERCP in patients with suspected biliary disease? A prospective trial and cost analysis Am J Gastroenterol 2001; 96: 2900-2904

[23] Tse F, Liu L, Barkun AN et al. EUS: a meta-analysis of test performance in suspected choledocholithiasis. Gastrointest Endosc 2008; 67: $235-244$

[24] Liu CL, Lo CM, Chan JK et al. EUS for detection of occult cholelithiasis in patients with idiopathic pancreatitis. Gastrointest Endosc 2000; 51: $28-32$

[25] Shimizu S, Tada M, Kawai K. Diagnostic ERCP. Endoscopy 1994; 26 : $88-92$

[26] Awadallah NS, Chen YK, Piraka C et al. Is there a role for cholangioscopy in patients with primary sclerosing cholangitis? Am J Gastroenterol 2006; 101: 284-291

[27] Huang SW, Lin CH, Lee MS et al. Residual common bile duct stones on direct peroral cholangioscopy using ultraslim endoscope. World J Gastroenterol 2013; 19: 4966 -4972

[28] Ando T, Tsuyuguchi T, Okugawa T et al. Risk factors for recurrent bile duct stones after endoscopic papillotomy. Gut 2003; 52: 116-121

[29] Cheon YK, Lehman GA. Identification of risk factors for stone recurrence after endoscopic treatment of bile duct stones. Eur J Gastroenterol Hepatol 2006; 18: $461-464$

[30] Saito M, Tsuyuguchi T, Yamaguchi T et al. Long-term outcome of endoscopic papillotomy for choledocholithiasis with cholecystolithiasis. Gastrointest Endosc 2000; 51: 540-545

[31] Tsuchiya S, Tsuyuguchi T, Sakai Y et al. Clinical utility of intraductal US to decrease early recurrence rate of common bile duct stones after endoscopic papillotomy. J Gastroenterol Hepatol 2008; 23: 1590 1595 